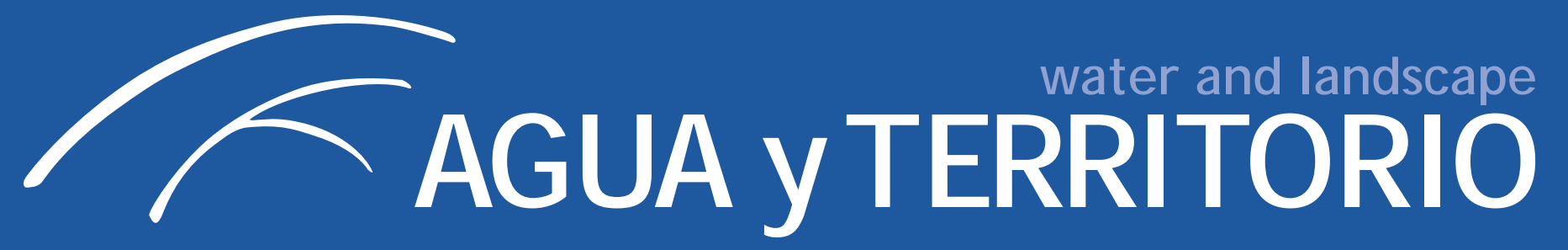

\title{
Rafael Borja Padilla
}

\author{
Investigador Científico del Instituto de la Grasa \\ (Consejo Superior de Investigaciones Científicas), Sevilla, España. \\ Investigador Responsable del Grupo de Investigación Aprovechamiento \\ de Subproductos y Tratamiento de Residuos \\ (Departamento de Biotecnología de los Alimentos)
}

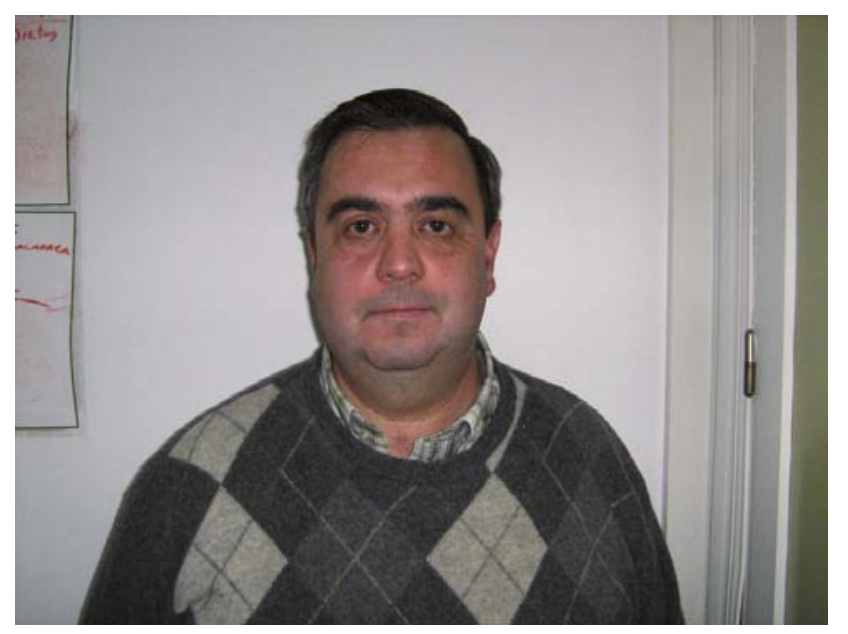

¿Cómo se produjo su vinculación con el ámbito de la producción del aceite?

Estoy vinculado a este sector desde el año 1986, año en el que me incorporé al Instituto de la Grasa (CSIC) con una beca de Formación de Personal Investigador (FPI) para realizar mi tesis doctoral a través de una beca financiada por la Junta de Andalucía.

El agua, pese a lo que pudiera parecer en un primer momento, tiene una especial vinculación con el proceso de elaboración del aceite, pero ¿en qué diferentes fases de su elaboración interviene el agua como elemento determinante de la calidad del producto final?

En el proceso de elaboración de aceite de oliva por centrifugación en dos fases, el agua interviene en dos etapas fundamentales del proceso: en el lavado de la aceituna (previamente a su molido) y en el lavado del aceite en las centrífugas verticales al final del proceso de elaboración. En el sistema de elaboración por centrifugación en tres fases, se utiliza también en el decanter (3 fases), para favorecer
J esús R. Navarro-García

la separación de la fase oleosa (aceite) y de la fase sólida (orujo), obteniéndose en este caso los alpechines clásicos, efluentes que desaparecen como tales en el proceso en dos fases. En esta etapa se añade aproximadamente 1 litro de agua/ kg de aceituna procesada.

¿Qué fases de la elaboración del aceite en las almazaras son más consumidoras de agua?

Como he comentado antes, en el sistema de dos fases las etapas más consumidoras de agua son el lavado de aceituna y el lavado de aceite. En el sistema de tres fases, además de en estas dos etapas anteriores, se consume bastante agua (aproximadamente 1 litro por kg de aceituna molturada) en la centrífuga horizontal o decanter.

¿Nos podría caracterizar las ventajas e inconvenientes que tiene el lavado de la aceituna destinada a la elaboración del aceite? ¿Qué problemas de contaminación puede generar y cómo influye en la calidad del aceite el lavado de la aceituna?

El lavado de la aceituna previo al proceso de elaboración del aceite de oliva tiene una importancia primordial, ya que permite eliminar impurezas, restos de polvo, hojas y trozos de ramas que, normalmente, acompañan a la aceituna tras su recolección. Ello permite eliminar problemas durante el procesado de la misma y mejora la pureza y calidad del aceite obtenido.

¿Qué problemas principales genera la producción del aceite en cuanto a contaminación y qué papel ocupan en ellos la generación de orujos y alpechines?

En el sistema de tres fases, el principal problema de contaminación viene dado por el alpechín (suma de las aguas de lavado más el agua de vegetación de la aceituna,

(c) Universidad de J aén / Seminario Permanente Agua, Territorio y Medio Ambiente (CSIC) 


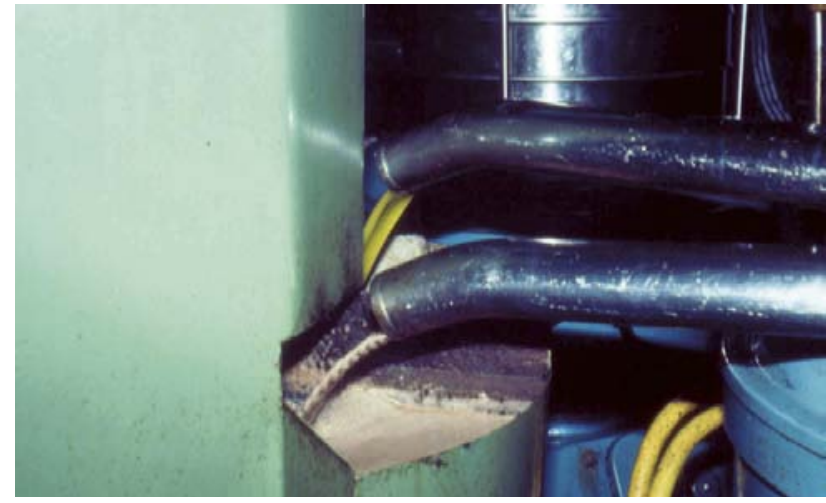

Proceso de lavado de aceite.

que corresponde aproximadamente al $50 \%$ del fruto). Este efluente tiene una elevada carga contaminante, con valores de demanda química de oxígeno (DQ0) que pueden estar comprendidos entre 50-100 g/l.

En el sistema de dos fases, los efluentes residuales corresponden a las aguas de lavado de aceitunas y las de lavado de aceite, produciéndose en cantidades muy inferiores al alpechín, con valores de 0,25-0,50 litros de aguas de lavado/ $\mathrm{kg}$ de aceituna procesada, siendo su carga contaminante (DQO menor a $20 \mathrm{~g} / \mathrm{I}$ ) muy inferior a la de los alpechines tradicionales.

En estos sistemas de dos fases, el principal problema lo representa el alperujo (suma del agua de vegetación más la pulpa y hueso), que representa aproximadamente el $80 \%$ del contenido total de la aceituna.

\section{¿Qué medidas se han implementado para corregir estos contaminantes?}

Actualmente las aguas de lavado se almacenan en balsas o bien se tratan mediante sistemas físico-químicos, la combinación de estos con sistemas de membranas (ultrafiltración y ósmosis inversa) o con procesos de oxidación avanzada.

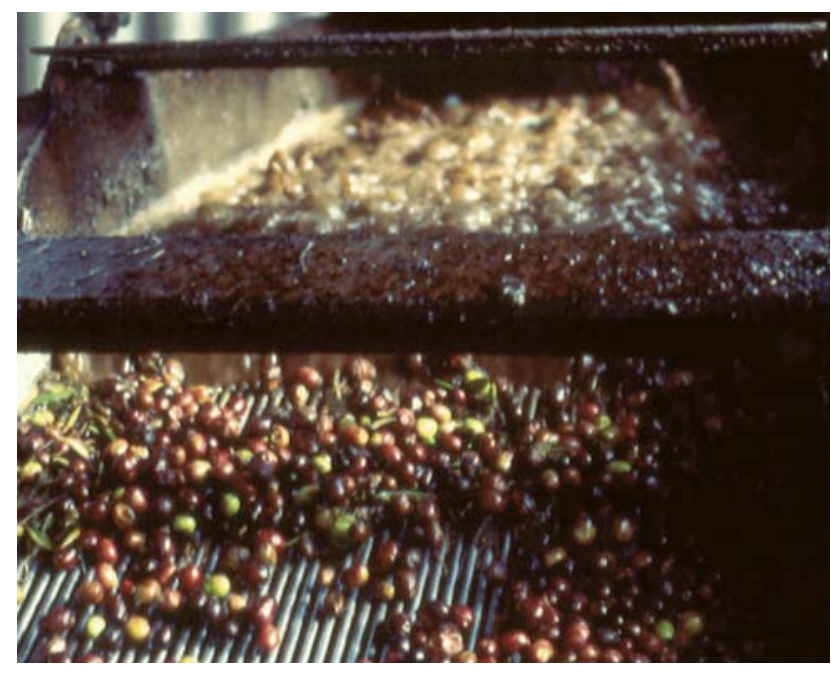

Proceso de lavado de aceitunas
Actualmente el alperujo se aprovecha mediante la aplicación de procesos de cogeneración para la obtención de energía eléctrica y calorífica simultáneamente. Se están estudiando también otras alternativas para su aprovechamiento, por ejemplo para la obtención de compost, obtención de compuestos de valor añadido mediante procesos de hidrólisis térmica con vapor, obtención de biogás mediante digestión anaerobia, etc.

\section{¿Cómo influyen los procesos de centrifugación en la generación de estos residuos contaminantes de nuestras aguas?}

Como ya he comentado, en la centrífuga horizontal 0 decanter del proceso en tres fases se obtienen los al pechines clásicos, mientras que en el proceso en dos fases, dado que no se añade agua al decanter, los efluentes mayoritarios se generan en la centrífuga vertical durante el lavado del aceite.

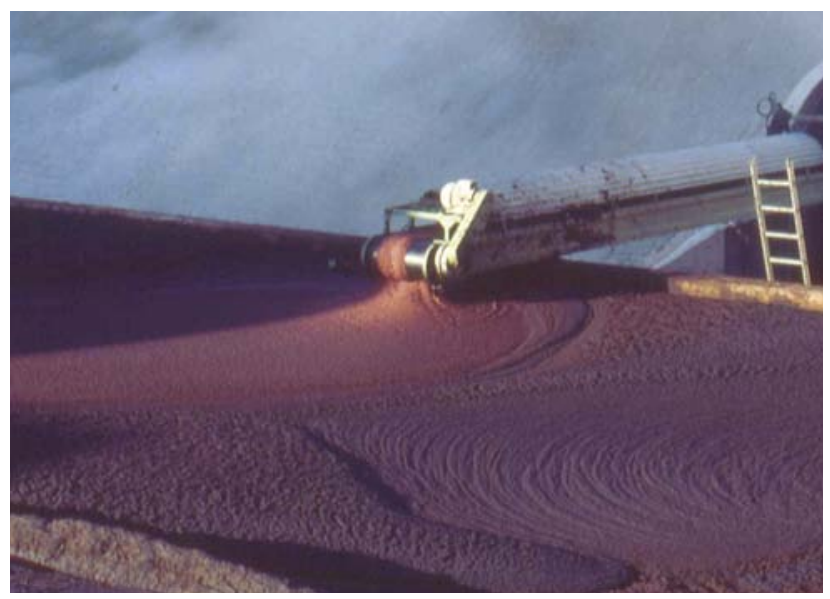

Balsa de almacenamiento de alperujo.

¿Nos podría hablar de los resultados que ha tenido la construcción de balsas de evaporación de alpechín y de su capacidad de recuperación de agua para el proceso de elaboración de aceite en las almazaras?

La implantación de balsas de evaporación fue la primera medida que se arbitró para eliminar los alpechines tradicionales. Permitían la eliminación de la mayor parte de estos efluentes por evaporación del agua durante los meses de primavera y verano. Sin embargo, estas balsas presentaron algunos problemas importantes: posibilidad de contaminación de aguas subterráneas (en caso de nulo o mal revestimiento), problemas de olores (debido a fenómenos de autofermentación natural que tienen lugar en ellas), escasa capacidad, etc.

En la actualidad, algunas almazaras las utilizan para eliminar las aguas de lavado de aceitunas y aceite, resultantes del proceso en dos etapas, proceso actualmente implantado en más del noventa por ciento de las almazaras españolas. 


\section{¿Qué problemas principales de contaminación genera la} elaboración de aceitunas de mesa?

La contaminación generada por el proceso de elaboración de aceitunas de mesa tiene que ver con los vertidos, entre los que destacan las lejías de cocido, aguas de lavado y salmuera de fermentación, generándose de cada uno de ellos aproximadamente $0,5 \mathrm{l} / \mathrm{kg}$ aceituna procesada. Claro está que la carga contaminante final de estos vertidos va a depender de la variedad de la aceituna procesada, de la concentración de sales empleada, etc.

¿Cuáles son los principales retos que tienen por delante las almazaras españolas para reducir los contaminantes que afectan al agua?

Hoy en día se centran en la reducción del volumen de agua utilizado en el lavado de la aceituna al inicio del proceso y en la centrífuga vertical para el lavado de aceite. Por

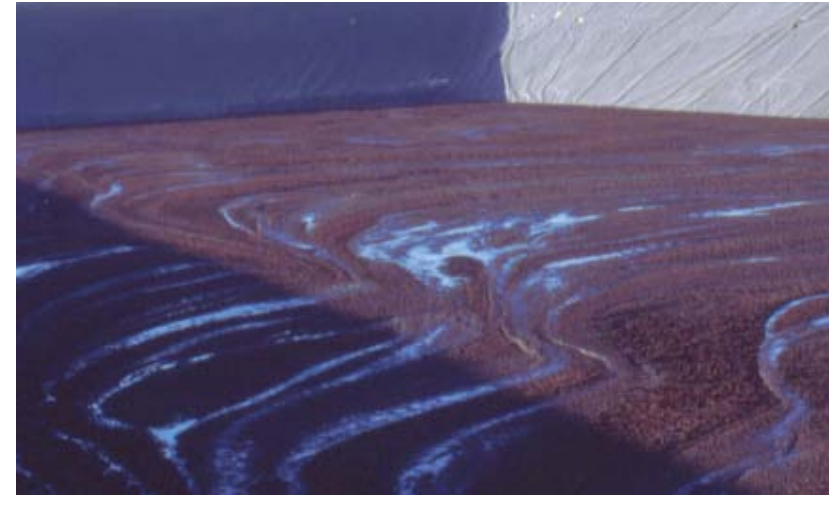

Balsa de almacenamiento de alperujo.

ejemplo, actualmente se están empleando en las almazaras de dos fases nuevas máquinas lavadoras en las que se puede reducir de forma considerable el consumo de agua para el lavado de la aceituna, lo que puede reducir el volumen final de aguas residuales generadas. 